\section{Revision of the Silver Book}

The revision of the Silver Book, the Compendium of Terminology and Nomenclature of Properties in Clinical Laboratory Sciences, is a joint project between IUPAC and the International Federation of Clinical Chemistry and Laboratory Medicine (IFCC). The project will result in the publication of a hardcopy and online version of the Silver Book.

Since its original publication in 1995, many significant developments have occurred in the field of clinical laboratory sciences, and in metrological concepts, definitions, and terms. Several branches of the clinical sciences have expanded and some new disciplines have appeared, necessitating additional coverage in the Silver Book. These new sections will be based upon recommendations published by various national, regional, and international bodies. Particularly, recent publications of IUPAC, IFCC, standards of ISO and CEN, and of the International Vocabulary of MetrologyBasic and General Concepts and Associated Terms, 3rd edition, must be considered for the new version.

Another reason for revising the Silver Book is that the interrelationships between various disciplines (the traditional and the recently developed) applied in the clinical laboratory are more and more frequent
Information about new, current, and complete IUPAC

projects and related initiatives. and necessary, not only from a scientific point of view, but also in practice (i.e., for an accurate diagnosis or prognosis). This evolution needs a common structure and language for data transfer to ensure an accurate exchange of information between the laboratory professional and the clinician.

Another key purpose of the revised Silver Book is to illustrate the list of the properties with examples taken from the IUPAC/IFCC Nomenclature, Properties, and Units database. Conversely, the principles of an updated Silver Book will be useful for the future development of the database. The structure and proposed contents of the book are presented on the project webpage available at the address below.

The project task group consists of experts from Canada, Denmark, France, Japan, Spain, and the USA.

For more information and comments, contact Georges Férard <georges.ferard@ noos.frs.

\section{www.iupac.org/web/ins/2007-033-3-700}

This project proposes to approach the problem via a public wiki site, following the lead of Kermit Murray's project on mass spectrometry. Using previous compilations as a starting point, the task group will post suggested definitions, and allow the community to comment and change (not indelibly). At the end of the consultation period, the task group will try to compile the results and publish IUPAC recommendations.

This project is a scoping exercise to determine if the "wiki" approach is likely to succeed, and to determine how the glossary can be cross referenced. Later projects will concentrate on finalizing the glossary, and perhaps writing a chapter of the Orange Book.

The first task group meeting took place during the CAC2008 conference in Montpellier, France (2 July 2008). The task group chair addressed a plenary session of the conference to announce and publicize the project. The second and final face-to-face meeting will be at the General Assembly in Glasgow in 2009.

For more information and comments, contact Brynn Hibbert <b.hibbert@unsw. edu.au>.

iii. www.iupac.org/web/ins/2008-002-1-500 